\title{
O Fenômeno Cultural do Misticismo Quântico: possibilidades e perspectivas de investigação
}

\author{
Marcia Tiemi Saito*
}

\section{Resumo}

O fenômeno cultural do misticismo quântico tem provocado reações diversas entre físicos, educadores e pesquisadores da área de Ensino de Física, pela grande popularização que o termo "quântico" adquiriu nas últimas décadas, em âmbitos que transcendem a área da física. Trata-se de um fenômeno complexo e multifacetado, que toca em questões como a natureza da ciência, as fronteiras entre o conhecimento científico e o não científico, questões de fundamentos da Física Quântica e suas implicações para a ciência e para a Educação Científica (EC). O objetivo do presente trabalho é apresentar um panorama dos principais temas relacionados a esse fenômeno, que têm sido explorados nos últimos anos, a fim de identificar novas possibilidades de pesquisa. Para isso, os temas serão apresentados a partir das perspectivas histórica, filosófica, social e educacional. Conclui-se que ainda existem muitas possibilidades de análise desse fenômeno, nas áreas de história, filosofia e sociologia da ciência e na compreensão e na busca de soluções para os seus impactos na ciência e na EC. Espera-se que este trabalho possa contribuir para fornecer um panorama geral dos problemas em aberto, que seja um ponto de partida para novas investigações e que inspire outros pesquisadores a explorarem o tema.

Palavras-chave: Física Quântica, Misticismo, Popularização da Ciência, Circulação do Conhecimento, Ciência e Cultura.

* Doutora em Ciências com concentração em Ensino de Física pela Universidade de São Paulo. Docente no Instituto Federal do Paraná, Campus Foz do Iguaçu, Brasil. E-mail: marcia.saito@ifpr.edu.br

ORCID: https://orcid.org/0000-0002-3959-4833

https://doi.org/10.5335/rbecm.v4i3.12903

http://creativecommons.org/licenses/by-nc-nd/4.0

ISSN: 2595-7376 


\section{Introdução}

O fenômeno cultural do misticismo quântico é um fenômeno bem conhecido entre físicos, educadores e pesquisadores da área de Ensino de Física, que costuma provocar reações diversas, desde interesse e curiosidade, passando pelo rechaço, a indiferença até a ridicularização, o desprezo e o combate de caráter dogmático (PESSOA JR, 2011; SAITO, 2019). Este fenômeno se evidencia e pode ser considerado como um "fenômeno cultural", principalmente pela grande popularização que o termo "quântico" adquiriu nas últimas décadas, em âmbitos que transcendem a área da física, se manifestando em diferentes setores da cultura e da sociedade, como as artes, a literatura, a medicina, a psicologia, a religião, a política, o direito, entre outros (MOURA; SANTOS, 2017).

Em uma simples pesquisa em sites de busca na internet, por exemplo, é possível encontrar cerca de 9 milhões de entradas para o termo "medicina quântica"; 3 milhões para "cura ou terapia quântica"; 6 milhões para "psicologia quântica", 3 milhões para "mente quântica" e quase o mesmo número para "tantra quântico" (CRUZ, 2011). Além desses resultados, também é comum encontrar diversos produtos sendo comercializados e que também fazem alusão ao termo "quântico", como livros, apostilas, cursos (inclusive, de pós-graduação), workshops, florais, suplementos nutricionais, entre outros (ROCHA, 2015; OLIVEIRA, 2018). Devido a essa ampla popularização e ao fato de que, na maioria das vezes, a palavra "quântica" aparece vinculada a uma espécie de misticismo ou espiritualismo, esse fenômeno acabou ficando conhecido como "misticismo quântico" (GRIM, 1982; PESSOA JR, 2011).

Contudo, diante dessa ampla popularização e das reações da comunidade de pesquisadores diretamente afetada, surgem alguns questionamentos: qual a origem desse fenômeno? Seria razoável supor que ele surgiu de forma totalmente independente da história da própria Física Quântica (FQ) e do contexto de sua formulação? Será que podemos ter controle sobre os usos que são feitos das teorias científicas?

Trata-se, portanto, de um fenômeno complexo, que toca questões que envolvem a natureza do conhecimento científico, as fronteiras com o conhecimento não científico, os efeitos sociais da circulação das teorias científicas, questões filosóficas e de fundamento da própria FQ, as suas implicações para a Educação Científica (EC), entre outras. 
Apesar da amplitude e da complexidade das questões envolvidas, nota-se que elas podem ser agrupadas em perspectivas de análise específicas, que, ainda que se sobreponham em alguns aspectos, podem ser delimitadas de acordo com a sua natureza preponderante. Sendo assim, o objetivo do presente trabalho é apresentar um panorama dos principais temas relacionados ao fenômeno cultural do misticismo quântico, que têm sido explorados nos últimos anos, a fim de identificar diferentes possibilidades de investigação.

Para isso, será feito um mapeamento dos principais temas ligados ao fenômeno cultural do misticismo quântico, a partir das seguintes perspectivas: (1) Perspectiva histórica, que visa explorar as origens histórico-sociais do fenômeno; (2) Perspectiva filosófica, a qual visa identificar debates e correntes filosóficas envolvidos no surgimento e no desenvolvimento do misticismo quântico; (3) Perspectiva social e educacional, que busca identificar e compreender as implicações sociais do fenômeno, em especial, para a Ciência e para a EC, identificar as comunidades, interesses e disputas envolvidos, e refletir sobre possibilidades discutir e problematizar os diferentes aspectos desse tema em sala de aula.

Por fim, é importante ressaltar que o presente trabalho não pretende esgotar o assunto e suas possibilidades de análise, mas trazer um panorama inicial a respeito de algumas delas. Dessa forma, espera-se que esse mapeamento inicial possa ser ampliado posteriormente, a fim de aprofundar a compreensão desse complexo e multifacetado fenômeno.

\section{Perspectiva Histórica}

Explorar o fenômeno cultural do misticismo quântico, do ponto de vista histórico, pode ser bastante enriquecedor para a reflexão a respeito dos possíveis desdobramentos sociais e culturais da circulação do conhecimento científico. Principalmente, porque sua história reúne tanto períodos em que se evidenciam as influências do contexto sociocultural na formulação de uma teoria científica específica - a FQ - quanto períodos em que, ao contrário, os debates presentes na sua formulação podem influenciar a sociedade e a cultura no geral, dando origem a novos usos e interpretações desta, inclusive não científicos.

A história da FQ pode ser separada em três estágios de elaboração (PATY, 2005). O primeiro deles (de 1900 a 1916), se refere à quando a FQ foi constituída como um 
novo domínio para os fenômenos e sistemas físicos, mostrando a sua especificidade e correspondência a um campo do conhecimento próprio. Esse período é caracterizado por um confronto entre a teoria clássica vigente naquele momento e os dados experimentais - como no estudo do problema da radiação de corpo negro, do efeito fotoelétrico, do calor específico dos sólidos, entre outros - na tentativa de compreender esse novo campo da física, o que caracterizaria o mundo microscópico e suas diferenças em relação ao mundo macroscópico (PATY, 2005). Nesse ponto, pode-se perceber o cerne de muitas das questões exploradas por alguns místicos quânticos: seria o estudo dos fenômenos quânticos uma "nova física"? O que exatamente caracterizaria esse novo campo da física? Qual a diferença entre a especificidade da FQ reconhecida pela física e a defendida por algumas linhas do misticismo quântico?

O segundo período da história da FQ (de 1917 a 1926), por sua vez, se refere ao estabelecimento da Mecânica Quântica (MQ) propriamente dita, sendo marcado pela elaboração de ideias, conceitos e esquemas mais precisos do ponto de vista teórico e mais abrangentes do ponto de vista experimental. Por um lado, o desenvolvimento da teoria nesse período se mostrou eficiente e poderoso com relação à formalização matemática, mas por outro, a descrição física correspondente não estava muito clara (PATY, 2005). Os diferentes formalismos da MQ elaborados nesse período possuíam distintas influências filosóficas. Por um lado, havia a tradição que se caracterizava por uma atitude mais positivista (ou "operacionista"), que se recusava em falar de grandezas não observáveis. Essa linha de pesquisa era conduzida principalmente pelos físicos Werner Heisenberg, Wolfgang Pauli, Max Born, Niels Bohr e Hendrik Kramers, e deu origem à Mecânica Matricial. Por outro, havia uma tradição caracterizada por uma postura realista, que se prendia fortemente a modelos visualizáveis, associados à Física Ondulatória Clássica. Essa linha de pesquisa partia do trabalho de Louis de Broglie, sobre a dualidade onda-partícula, e culminou na elaboração da Mecânica Ondulatória, por Erwin Schrödinger (PESSOA JR, 2006). A equivalência entre os dois formalismos foi demonstrada por Schrödinger, no próprio ano de 1926, porém pode-se dizer que as discussões de fundamento sobre como interpretar esse formalismo ainda permanecem em aberto, até os dias de hoje. Assim, a partir do estudo desse período da história da FQ, uma questão interessante a ser explorada seria o quanto e como a presença desses diferentes formalismos e influências filosóficas propiciaram direta ou indiretamente o desenvolvimento do misticismo quântico. Um ponto importante a ser destacado é que, em geral, no discurso dos místicos 
quânticos, aparece uma rejeição muito grande às posturas filosóficas taxadas como materialistas e uma defesa de posturas consideradas mais idealistas em relação à física e à ciência como um todo. Quais seriam exatamente as características dessas posturas? Será que há uma deturpação das características das correntes filosóficas materialistas e idealistas por parte dos místicos quânticos? Existiria uma relação que se buscou estabelecer entre essas influências filosóficas presentes na história da FQ e os discursos defendidos por eles?

Por fim, o terceiro período da história da FQ (de 1927 em diante) é caracterizado pelas tentativas de interpretar conceitualmente a estrutura teórica da MQ e pelos desenvolvimentos teóricos com relação à dinâmica dos processos quânticos. Uma particularidade desse período é que as interpretações não eram expressas somente em termos de um novo conteúdo físico para as entidades matemáticas, como nas teorias físicas precedentes na história, mas lidavam também com pressupostos e questões filosóficas relacionadas ao conhecimento científico, como o status da observação com relação ao conhecimento e à realidade, a distinção entre sujeito e objeto, a causalidade e o determinismo (PATY, 2005). Esse período é marcado por importantes desenvolvimentos teóricos - como o Princípio da Incerteza e o Teorema de Bell - por debates de cunho filosófico entre os físicos - como os famosos debates entre Einstein e Bohr - pela delimitação de alguns problemas de fundamento como o problema da medição - e pelo surgimento e esclarecimento das diferentes interpretações da FQ (KRAGH, 1999; FREIRE JR, 2015). Nesse período, portanto, ficam claros os principais debates sobre os fundamentos da FQ: os debates em torno da causalidade e do determinismo na FQ; sobre a completude, o realismo e a não-localidade; e sobre o problema da medição e o papel da consciência, os quais consistem nos principais problemas citados e explorados pelo misticismo quântico (SAITO, 2019). Dessa forma, ao investigar as raízes históricas do fenômeno cultural do misticismo quântico, é possível notar que muitos dos debates e argumentos elaborados pelos adeptos e propagadores desse fenômeno se encontram em lacunas e discussões dentro da própria FQ. Contudo, algumas questões possíveis de serem mais bem exploradas seriam: existe diferença entre o tratamento desses problemas por parte dos físicos e dos místicos quânticos? Por que algumas interpretações são reconhecidas pela física, sendo consideradas científicas, e outras não? Quais são as diferenças entre elas? Será que existe alguma deturpação dos conceitos e dos problemas de fundamentos da FQ, quando são abordados pelos místicos quânticos? 
Para uma investigação a respeito dessas questões históricas, referentes a como os debates presentes na comunidade da FQ acabaram influenciando na gênese e no desenvolvimento do fenômeno cultural do misticismo quântico, inicialmente, é importante compreender os próprios debates de fundamentos da FQ. Para isso, Kragh (1999) e Pessoa Jr (2006) fazem um bom panorama histórico sobre a história da FQ e seus problemas de fundamento. Para um enfoque mais filosófico conceitual, ver Jammer (1966), Beller (1999), Pessoa Jr (2003), Paty (2005). Para um panorama e relações mais concretas entre os problemas de fundamentos da $\mathrm{FQ}$ e suas implicações socioculturais, que culminaram no fenômeno do misticismo quântico, ver Freire Jr et al. (2011) e Saito (2019).

Além da influência histórica dos debates mais internos à comunidade da FQ, a respeito de seus problemas de fundamento, também houve a influência do contexto histórico-social mais amplo na gênese o no desenvolvimento da fenômeno cultural do misticismo quântico.

Um contexto histórico-social importante nesse processo é o contexto da República de Weimar (de 1918 a 1927), na Alemanha, momento anterior à consolidação da MQ. Forman (1983) conta que, nesse período, o ambiente intelectual predominante era hostil aos físicos, devido à tendência intelectual que passou a predominar nesse país, que consistia em uma "filosofia da vida" existencialista, neorromântica, que se alimentava de crises e era marcada pelo antagonismo em relação à racionalidade analítica e às ciências exatas e suas aplicações técnicas. Por conta disso, a atitude predominante dos cientistas alemães foi a de procurar acomodar seu discurso e a ideologia científica a esse ambiente intelectual hostil. Para Forman (1983), a ansiedade dos físicos alemães em reconstruir os fundamentos da física pode ser interpretada, pelo menos em parte, como uma reação ao prestígio negativo dessa ciência nessa época.

Após a Segunda Guerra Mundial, no contexto da Guerra Fria, a influência do contexto histórico-social no advento do fenômeno do misticismo quântico passou a ser um pouco mais direto. Nesse período, a Interpretação da Complementaridade da FQ passou a perder sua hegemonia, que havia perdurado aproximadamente de 1930 a 1940. Na URSS, as ideias de Bohr eram rejeitadas, por serem consideradas idealistas e, nos EUA, a atitude pragmática da maioria dos físicos não favorecia o entendimento mais profundo das suas ideias. Esse contexto favoreceu o surgimento de novas interpretações da FQ (FREIRE JR, 2015). 
Além disso, Kaiser (2011) ressalta que, nesse período, houve um aumento considerável na taxa de natalidade nos EUA e, consequentemente, em um grande número de jovens na década de 1960. No contexto da ciência e da tecnologia, as corridas espacial e armamentista contra a URSS causaram um aumento vertiginoso dos investimentos em ciência e EC por parte dos EUA, acarretando na formação de um número muito grande de jovens doutores em física. Contudo, já no final da década de 1960, com o advento da Guerra do Vietnã, esse investimento sofreu uma queda abrupta, o que gerou um aumento na taxa de desemprego e fez com que a maioria dos recém-doutores em física ficasse desempregada. Paralelamente a isso, nos anos 1960 e 1970, surgia o contexto da contracultura hippie, um período marcado por grandes mudanças culturais e agitação política - como o rock 'n roll, drogas, liberação sexual, preocupação com o meio ambiente, movimento feminista, os protestos contra a Guerra do Vietnã - no qual os jovens se posicionariam contra os valores da sociedade norte-americana da época. Esse contexto contracultural, aliado ao aumento do desemprego, possibilitou com que físicos formados em instituições acadêmicas de elite não seguissem carreiras acadêmicas convencionais e perseguissem seus interesses de pesquisa, buscando fontes de fomento alternativas e se organizassem em instituições acadêmicas não convencionais, como no Instituto Esalen e no Fundamental Fysiks Group, nos quais podiam discutir os problemas de fundamentos da FQ de forma mais livre (KAISER, 2011). Ao mesmo tempo em que isso foi importante para alguns avanços na $\mathrm{FQ}$, como o entendimento das consequências do Teorema de Bell, também possibilitou estudos alternativos, que buscavam vincular os fenômenos da FQ relacionados à não-localidade com a parapsicologia, à clarividência e à psicocinese, além da criação de movimentos, como o Movimento do Potencial Humano, que reuniu nomes como Fritjof Capra, Amit Goswami, Fred Allan Wolf e Gary Zukav, quem posteriormente se tornariam os precursores do fenômeno do misticismo quântico. Essas organizações não convencionais também tiveram um papel importante na gestação dos primeiros "produtos quânticos", como os workshops, cursos e palestras promovidos por seus membros (ROCHA, 2015).

Após esse período, no entanto, pode-se dizer que os protestos e as revoluções almejadas pelos jovens dos anos 1960 e 1970 não lograram modificar o mundo como esperado, e que muitas de suas conquistas acabaram sendo revertidas pela crise econômica dos anos 1970 e pelo crescimento do neoliberalismo, nos anos 1980 e 1990. Com isso, a contracultura se transformou na cybercultura e os movimentos 
de protesto, os ideais utópicos e o anticonsumismo, característicos da contracultura hippie, posteriormente, acabaram se rendendo ao individualismo, ao narcisismo e ao consumismo promovidos pela indústria cultural. Essas mudanças se refletiram no contexto mais específico, e fizeram com que o Movimento do Potencial Humano, das décadas de 1960 e 1970, se transformasse no Movimento da Nova Era e do Neoesoterismo, dos anos 1980 e 1990, um movimento progressivamente mais apolítico, conformista e muito mais próximo à literatura de autoajuda (ROCHA, 2015). Heelas (1996) descreve o Movimento da Nova Era como epistemologicamente individualista, no qual a sabedoria interior do indivíduo serve como fonte guia para as suas condutas e para se liberar do passado e de tradições internalizadas. Esse movimento também é caracterizado por um perenialismo, que defende que as verdades já se encontravam no coração de diferentes tradições, da xamânica ao budismo. Já a expressão "Neoesoterismo" é utilizada por Magnani (1999), para caracterizar a forte expansão e disseminação das práticas comumente agrupadas sob a denominação de "esotéricas", incluindo uma ampla gama de produtos, atividades e serviços, e constituindo um fenômeno de caráter verdadeiramente mercadológico.

A partir do resgate desses diferentes contextos históricos, é possível notar a permanência de algumas ideias, atitudes e concepções, ao longo destes, que ganham ou perdem força, de acordo com uma predisposição social mais ampla. Algumas delas, como uma atitude neorromântica e antimaterialista diante dos fenômenos naturais e sociais, somadas a uma predisposição social favorável, possibilitaram o advento do fenômeno cultural do misticismo quântico. Contudo, ainda cabe aprofundar alguns aspectos: quais outros contextos histórico-sociais que também poderiam ter influenciado no surgimento do misticismo quântico? Após o seu surgimento, como ele se desenvolveu? Quais os períodos históricos e as condições específicas que permitiram que ele ganhasse mais força e se propagasse na cultura? A sua força e influência permanecem as mesmas até os dias atuais?

Outro aspecto importante que pode ter influenciado no advento e na consolidação dos discursos do misticismo quântico, uma vez que são fatores frequentemente mencionados por eles, são as inclinações místicas ou as influências filosóficas idealistas em alguns físicos fundadores da FQ. Um dos exemplos mais mencionados por místicos quânticos é a simpatia que Niels Bohr apresentou em alguns momentos de sua trajetória pelas filosofias orientais, o que se refletiu no brasão que desenhou para si, em 1947, ao ser condecorado com o título de cavaleiro pelo rei 
da Dinamarca, que incluía o símbolo chinês do t’ai-chi, associado ao taoísmo, que representa o equilíbrio entre a ação dos princípios complementares de yin e yang, como uma evocação gráfica ao seu Princípio da Complementaridade (CAPRA, 1975; NOGUEIRA, 2010). Outro exemplo bastante mencionado pelos místicos quânticos é a admiração que Heisenberg tinha pela filosofia platônica e as suas críticas à filosofia materialista (WILBER, 1984). Outros casos bastante mencionados pelos místicos quânticos são: a amizade que David Bohm tinha com o filósofo e escritor indiano Jiddhu Krishnamurti e a sua defesa do conceito de totalidade na FQ (FREIRE JR, 2015), e as defesas sobre o papel de um observador consciente em uma medida por parte dos físicos John von Neumann, Fritz London, Edmond Bauer e Eugene Wigner (PESSOA JR, 2001). Por fim, um exemplo mais contemporâneo seria o do físico brasileiro Mario Schenberg, que escreveu o prefácio da edição brasileira do livro O Tao da Física, no qual demonstra um grande entusiasmo pela abordagem de Capra. Considerando que o Brasil é um dos países em que o fenômeno cultural do misticismo quântico ganhou mais ampla repercussão, seria interessante investigar o quanto o contexto em que Schenberg estava imerso influenciou nessa repercussão. Assim, diante dessas inclinações dos físicos mencionados, podemos nos questionar: o que ou qual o contexto que levou esses físicos a apresentarem essas inclinações e concepções? Como elas de fato influenciaram o advento do misticismo quântico? Será que as menções das posturas e influências filosóficas desses físicos por parte dos místicos quânticos é fidedigna ao seu pensamento? Qual seria a diferença entre as inclinações de físicos como Bohr, Bohm e Schenberg e a postura de físicos notadamente místicos quânticos, como Amit Goswami?

Além das influências elencadas anteriormente, um estudo que se proponha a investigar o surgimento do fenômeno cultural do misticismo quântico, a partir de uma perspectiva histórica, não pode deixar de se debruçar sobre os seus principais precursores. O primeiro deles é o físico austríaco Fritjof Capra, com a publicação de seu famoso livro O Tao da Física, em 1975, o qual é considerado, até os dias atuais, a obra mais vendida do gênero: já foi traduzida para 23 idiomas e possui 43 edições. Assim, Capra pode ser considerado um dos precursores do misticismo quântico, não apenas pelo conteúdo de sua obra, mas principalmente pela sua repercussão. De fato, se considera que Capra, com essa obra, criou um autêntico novo gênero literário, que passou a relacionar as questões da Física Moderna (FM) com o misticismo oriental, introduzindo o que se denominou de "paralelismo quântico". Capra 
também fez parte do movimento da contracultura hippie, nos EUA, nos anos $1970 \mathrm{e}$, diferentemente de outros físicos que escrevem sobre questões filosóficas relacionadas à física, escreve como um popularizador de ciências, voltando-se para a cultura de massas (ROCHA, 2015). Ao analisar O Tao da Física, é possível notar a presença de um certo orientalismo ${ }^{1}$, que idealiza o pensamento oriental com a finalidade de criticar a sociedade ocidental, além de ficar clara a presença dos discursos da Nova Era, em que se busca contrapor um "velho" paradigma (que corresponderia à FC) a um "novo" paradigma (que corresponderia à FM), supostamente melhor e mais interessante em diversos aspectos. Ele também cita conceitos e discute questões relacionadas aos problemas de fundamentos da FQ, como a dualidade onda-partícula, o problema da medição e o conceito de potencialidade de Heisenberg, além de fazer menção às tendências místicas de alguns físicos, como Wheeler, Wigner, Bohr e Bohm, porém busca explicitar que não defende uma união entre ciência e misticismo (SAITO, 2019).

Outro autor importante no surgimento e consolidação do misticismo quântico foi o médico indiano Deepak Chopra, com a publicação de seu livro A Cura Quântica, de 1989. Pela publicação deste livro, em 1998, Chopra também recebeu o prêmio satírico Ig Nobel de Física (IMPROBABLE RESEARCH, 1998). Em termos de vendas dos chamados "produtos quânticos", Chopra pode ser considerado o mais bem sucedido de todos, com mais de 60 obras publicadas e 10 milhões de cópias vendidas, somente em língua inglesa (HAMMER, 2004). Diferentemente de Capra, Chopra não possuía formação em física e, por conta disso, acaba utilizando os argumentos de Capra com um status bem estabelecido e se utilizando de uma física já popularizada, para aplicação em sua área de formação (como em questões relacionadas à saúde e ao bem estar), e utilizando argumentos de autoridade. Com isso, Chopra vai mais além do que Capra, fazendo analogias entre fenômenos da FQ e da medicina alternativa e defendendo que os primeiros explicariam os segundos. Para isso, ele faz menção aos conceitos e problemas da FQ e às inclinações místicas de alguns físicos, não menciona a existência de diferentes interpretações para a FQ e apresenta uma postura de rejeição ao intelecto e à razão, em detrimento de uma valorização do sentimento e da intuição. Assim, seu discurso também se coloca dentro do movimento da Nova Era e apresenta aspectos do orientalismo, ao contrapor o "velho" paradigma (correspondente à ciência materialista) ao "novo" 
(correspondente aos saberes tradicionais de origem mística), o qual seria respaldado pela FQ (SAITO, 2019).

Por fim, outro precursor do fenômeno do misticismo quântico a ser mencionado é o físico indiano Amit Goswami, que ficou famoso por sua participação no documentário "Quem somos nós" e pelas suas aplicações da FQ à diversas questões da vida, saúde, economia e sociedade. Goswami possui grande influência no Brasil, por suas visitas regulares a este país. Devido à sua formação em física, em suas obras iniciais, Goswami une um pouco do cuidado prezado por Fritjof Capra com relação aos conceitos da FQ com a busca por extrapolar essa teoria e aplicá-la a outras áreas do conhecimento, procurada por Deepak Chopra. Em sua primeira obra vinculada ao misticismo quântico, O Universo Autoconsciente, de 1993, Goswami busca elaborar uma interpretação da FQ própria, baseada em uma filosofia idealista, na qual a consciência exerceria um papel central. Ele também apresenta os problemas de fundamentos da FQ em detalhe, discutindo as controvérsias envolvidas, porém ele acaba introduzindo modificações sutis em algumas interpretações da FQ. Em sua obra, também é possível observar o discurso da Nova Era, que contrapõe um "velho" paradigma (correspondente ao realismo materialista) a um "novo" (correspondente à sua filosofia idealista). Por fim, ele também se utiliza de argumentos de autoridade, faz referência às inclinações místicas de alguns físicos e à experimentos que envolvem a consciência, para respaldar seus argumentos. Em suas obras posteriores, Goswami passa a aplicar a sua filosofia idealista a diversas áreas da vida humana e a fazer uma simplificação das questões de fundamentos da FQ, omitindo os seus debates e diferentes interpretações. A partir deste ponto, também fica claro o caráter mercadológico de suas obras e produtos quânticos - como cursos, palestras e workshops, os quais não possuem preços muito acessíveis - e que a FQ passa a ter um papel secundário, surgindo apenas como um símbolo de autoridade persuasiva (SAITO, 2019).

Diante desses aspectos presentes nas obras desses autores, é possível observar que há suporte para a defesa de que os elementos históricos apresentados anteriormente - tanto dos debates de fundamentos da $\mathrm{FQ}$, quanto dos contextos histórico-sociais mais amplos - podem ter influenciado no advento e na consolidação do misticismo quântico. Porém, ainda é possível aprofundar algumas questões: quais outros precursores e personagens do misticismo quântico são relevantes de serem analisados? Quais os impactos de suas obras no surgimento e no desenvolvimento 
desse fenômeno cultural? Como esses personagens interagiam entre si? É possível caracterizá-los dentro de uma comunidade relativamente homogênea ou há diferenças relevantes entre eles? Quais as diferenças entre o funcionamento e os discursos desses personagens e dessa comunidade em relação à comunidade da FQ?

Para uma investigação mais aprofundada a respeito dessas questões históricas contextuais mais amplas que possibilitaram o surgimento do misticismo quântico, ver Forman (1983), sobre o contexto científico na República de Weimar; Freire Jr (2015), sobre o contexto que propiciou o surgimento de novas interpretações da FQ; Kaiser (2011) e Rocha (2015), sobre as influências da contracultura hippie na FQ; Heelas (1996), Magnani (1999) e Hammer (2004) sobre o movimento da Nova Era e do Neoesoterismo; Wilber (1984) e Marin (2009) sobre as inclinações místicas de alguns físicos; Grim (1982), Costa (2013), Rocha (2015) e Pigozzo et al. (2019) sobre Fritjof Capra; Hammer (2004) e Saito e Gurgel (2017) sobre Deepak Chopra; Nogueira (2010) sobre Amit Goswami; Machado (2017) e Saito (2019) sobre uma análise das obras dos precursores do misticismo quântico; e Cruz (2011) sobre uma análise cultural mais ampla.

\section{Perspectiva filosófica}

Desde o surgimento até o desenvolvimento do fenômeno cultural do misticismo quântico, diversas questões filosóficas são suscitadas. Explorar essas questões pode contribuir para a compreensão do funcionamento e da natureza da ciência e, em particular, da FQ, dos limites que separam o conhecimento científico do não científico e dos efeitos e implicações da circulação do conhecimento científico. Sendo assim, as primeiras questões filosóficas a serem exploradas, relacionadas a esse fenômeno, são as questões referentes aos próprios debates sobre os fundamentos da FQ, como os debates sobre a causalidade e o determinismo na FQ, sobre a completude, o realismo e a não-localidade, e sobre o problema da medição e o papel da consciência, os quais também deram origem às diferentes interpretações da FQ. Todos esses aspectos também são bastante explorados e citados pelos místicos quânticos.

Os debates sobre a causalidade e o determinismo na FQ começam principalmente com as publicações, em 1926, da Interpretação probabilista de Born para a MQ e, em 1927, do Princípio da Incerteza de Heisenberg. A Interpretação probabilista considera que a função de onda determina um conjunto probabilístico, enquanto 
os resultados das medidas são os eventos individuais, também fornece a chamada Regra de Born, na qual a função de onda seria regida pela equação de Schrödinger (determinista) e o seu módulo ao quadrado forneceria a probabilidade de se obter uma determinada medida. Dentro da Interpretação ondulatória, ela rege o "colapso da função de onda" (indeterminista e descontínuo), que ocorreria ao se realizar uma medição. Essa interpretação causou um sentimento de insatisfação em Einstein, que, em 1926, escreve a sua famosa carta endereçada a Born, onde ele expressa seu "sentimento interno" de que "Deus não joga dados". O Princípio da Incerteza de Heisenberg, por sua vez, estabelece que é impossível preparar estados onde a posição e o momento são simultaneamente e arbitrariamente bem determinados. Isso rompe com o determinismo clássico, pois, uma vez que não é possível conhecer de forma exata os valores inicias, consequentemente, não será possível por princípio estabelecer regras que prevejam os eventos futuros de forma exata (KRAGH, 1999).

Já os debates sobre a completude, o realismo e a não-localidade se iniciam em 1927, com as críticas de Einstein à interpretação estatística, na Academia Prussiana de Ciências. Após isso, no mesmo ano, no $5^{\circ}$ Congresso de Solvay, acontecem os famosos debates entre Einstein e Bohr, nos quais Einstein demonstra a sua insatisfação com relação à Interpretação da Complementaridade. As críticas de Einstein se deviam ao caráter operacionista e positivista desta interpretação, que, a seu ver, escondia as dificuldades conceituais da FQ. Posteriormente, em 1935, Einstein publica, juntamente com os físicos Boris Podolsky e Nathan Rosen, o artigo sobre o famoso paradoxo EPR, o qual tentava mostrar que a MQ, como descrição física da realidade, era incompleta. Para isso, os autores usaram duas hipóteses: o princípio de realidade e o princípio de localidade (KRAGH, 1999). Apesar do artigo EPR não ter convencido os físicos a abandonarem a Interpretação da Complementaridade naquele momento, ele foi importante, pois identificou um conceito especificamente quântico: a não localidade. Esse esclarecimento contribuiu para que, em 1965, John Bell mostrasse que três hipóteses gerais sobre o mundo físico - a localidade, a indução e o realismo - levam a previsões experimentais que, sob determinadas condições, são inconsistentes com as previsões da MQ. Em 1982, os experimentos de Alain Aspect concluíram pela não localidade dos sistemas quânticos (FREIRE JR, 2015).

Por fim, os debates sobre o problema da medição e o papel da consciência surgem justamente da oposição entre a evolução contínua e determinista da função de estado ou função de onda - regida pela equação de Schrödinger - e a evolução 
descontínua e indeterminista descrita pelo postulado da projeção de Von Neumann, normalmente chamada de "colapso da função de onda" ou "redução de estado". Ou seja, esse problema levanta as seguintes questões: como acontece a transição de um estado que contém uma superposição de duas ou mais possibilidades para um estado que contém somente uma? Ou, como e em que estágio da medição acontece $o$ "colapso da função de onda" ou "redução de estado"? (PESSOAJR, 1992). A resposta a essas questões e o papel atribuído ao sujeito na medição é que irão separar as interpretações de caráter mais idealista/subjetivista das interpretações de caráter mais realista (PESSOA JR, 2001).

Algumas respostas a essa questão atribuíam um papel especial para a observação na produção de mudanças em sistemas quânticos, podendo, portanto, ser consideradas mais idealistas/subjetivistas. Heisenberg, em 1927, foi talvez o primeiro a salientar o inevitável distúrbio causado pelo observador no sistema quântico observado. Um pouco mais tarde, Bohr escreveu a respeito da inevitável "interação" entre o "agente de observação" e o sistema quântico. Na interpretação ondulatória da MQ, este problema foi resolvido atribuindo-se ao ato da observação o poder de reduzir uma onda de probabilidade extensa para um pacote de onda estreito. $\mathrm{Na}$ Interpretação da Complementaridade, este problema é evitado com a utilização da premissa de que existe uma separação entre os mundos micro e macroscópico e que o aparelho macroscópico não é passível de descrição quântica, devendo ser descrito pela linguagem da FC (PESSOA JR, 1992). Em 1932, von Neumann formula a sua tese do conhecimento limitado, que, implicitamente, coloca como premissa que o que caracteriza uma "observação" é a presença de um observador inteligente ou consciente. Em 1939, London e Bauer defendem explicitamente que a consciência é que provocaria o colapso da função de onda, apesar dela não poder escolher qual seria o resultado da medição. Von Weizsäcker também apresenta uma concepção que renuncia ao princípio de objetividade, defendendo que a vontade do sujeito poderia afetar instantaneamente a realidade distante, com um argumento baseado em um "experimento de escolha demorada". Em 1935, John Wheeler também explora esse tipo de experimentos e desenvolve a noção de observador participante, segundo a qual observador seria capaz de fazer com que o passado se atualizasse no presente. No mesmo ano, Schrödinger elabora o seu famoso paradoxo do gato, cujo objetivo inicial era argumentar que a $\mathrm{MQ}$ era incompleta, contudo, acaba por explorar também a possibilidade de estender o idealismo de algumas interpretações para 
objetos macroscópicos. Em 1962, o físico Eugene Wigner elabora uma extensão desse paradoxo, que ficou conhecida como o problema do amigo de Wigner, o qual levaria a uma interpretação "solipsista", em que a realidade do mundo seria diferente para cada sujeito. Outra solução radical ao problema da medição seria apresentada em 1957, por Hugh Everett, e estendida, a partir de 1971, por Bryce DeWitt, a qual ficou conhecida como Interpretação de Muitos Mundos. Nela, não há colapso e os observadores passam a existir em mundos paralelos com os diferentes resultados, cada vez que uma medição é realizada (PESSOA JR, 2001; FREIRE JR, 2015).

Em oposição a essas interpretações com abordagens mais idealistas ou subjetivistas, a partir dos anos 1950, começam a surgir abordagens que buscavam eliminar o observador humano da descrição quântica da natureza, as quais podem ser classificadas como "realistas" ou "objetivistas". Dentre elas, podemos destacar a Interpretação dos Coletivos Estatísticos, que consiste em uma interpretação essencialmente corpuscular, na qual o vetor de estado descreve um coletivo estatístico de sistemas preparados identicamente, e o processo de redução da função de onda reflete a transferência do sistema objeto de um coletivo inicial para um de seus subcoletivos. Outra delas é a Interpretação causal de David Bohm, de 1952, que consiste em uma interpretação determinista, baseada em variáveis ocultas, a qual procura resolver o problema da medição através de uma modificação no formalismo da MQ. Por fim, o Programa de Amplificação Termodinâmica procura substituir o papel fundamental do sujeito humano pelo papel do aparelho de medição. Nele, a redução de estado se completa quando um registro macrofísico aparece, a partir de um processo termodinâmico irreversível de amplificação do sinal microscópico, o que faz com que o observador deixe de ser necessário nesse processo (PESSOAJR, 1992).

Considerando que existência desses debates e diferentes interpretações para a FQ é um fator bastante explorado pelo misticismo quântico, levantam-se as seguintes questões: existe alguma postura filosófica em relação à ciência que favoreceria o surgimento de interpretações místicas para a FQ? Como essas interpretações foram utilizadas pelos místicos quânticos? Será que houve distorções das mesmas? Haveria algum critério ou forma de distinguir interpretações da FQ aceitáveis cientificamente das não aceitáveis?

Com essas questões, toca-se em outro problema filosófico relevante, relacionado ao surgimento e desenvolvimento do misticismo quântico. Trata-se do problema da demarcação na ciência, que busca caracterizar o que diferencia a ciência das 
outras formas de conhecimento. Em relação ao fenômeno do misticismo quântico, especificamente, essa questão tomaria a seguinte forma: uma vez que o misticismo quântico possui raízes históricas no próprio desenvolvimento da FQ, ele poderia ser considerado científico? Seriam os seus argumentos e defesas apenas mais uma forma de interpretar a FQ? Quais as diferenças entre as suas interpretações e aquelas aceitas pela comunidade da física?

Sobre essas questões, Grim (1982) argumenta que a análise do problema da demarcação na ciência para o caso do misticismo quântico é um caso que versa sobre as implicações da FQ. $\mathrm{O}$ autor critica o paralelismo utilizado como método de análise por autores como Fritjof Capra e Gary Zukav e a distorção que eles fazem da ciência e do misticismo oriental, e apresenta as limitações de algumas premissas adotadas por esses autores em sua abordagem de caráter idealista. Costa (2013), Machado (2017) e Lima (2017) utilizam análise discursiva de obras relacionadas ao misticismo quântico e concluem que a linguagem e a argumentação apresentadas nesses livros se afastam da linguagem aceita pelo meio científico, pois, muitas vezes, se utilizam de metáforas inadequadas, fazem apropriações indébitas da FQ e utilizam argumentos de autoridade. Oliveira (2018) analisa outras obras e entrevista dois profissionais, que utilizam o termo "quântico" em seus serviços, e conclui que a FQ apresentada nos discursos empregados nesse meio é bastante adulterada em relação ao saber científico, repleta de bricolagens². Saito e Gurgel (2017) e Saito (2019) analisam se a cura quântica, de Deepak Chopra, e o misticismo quântico, de forma mais ampla, podem ser considerados científicos, a partir da filosofia da ciência de Ludwik Fleck, e concluem que suas estruturas se afastam das características dos coletivos de pensamento científicos e se aproximam dos coletivos de pensamento de caráter dogmático e dos coletivos que permitem e valorizam o exercício do livre pensar. Pessoa Jr (2013) analisa o típico argumento místico quântico relacionado à chamada "lei da atração", destrinchando cada uma das teses implícitas neste argumento, e conclui que o argumento é insustentável, por apresentar elementos incompatíveis com os resultados aceitos pela FQ. Por fim, Cruz (2011) faz uma análise cultural do misticismo quântico em diferentes momentos históricos, argumentando que atualmente seu discurso faz uso de propaganda, de argumentos que buscam uma legitimação e utiliza o conhecimento científico de forma instrumental com interesse mercadológico, por conta da pressão da indústria cultural. 
Tendo em vista essas diferenças entre o conhecimento da FQ e o discurso do misticismo quântico apontadas pelos autores mencionados, abre-se margem para outra questão filosófica importante envolvendo esse fenômeno: como lidar e dialogar com as diferentes posturas dos místicos quânticos frente à ciência estabelecida? Qual seria a postura mais adequada a ser adotada por físicos, filósofos e educadores em ciências em relação ao misticismo quântico?

Em relação à essas questões, Pessoa Jr (2011) esclarece que existem duas posturas de místicos em relação à ciência: o misticismo "desafiador" da ciência e o misticismo "conciliador" com a ciência. O primeiro aceita a existência de fenômenos que contradizem o que prevê a ciência estabelecida, já o segundo aceita somente a existência de entidades e processos que não entram em contradição com a ciência. Diante dessas posturas, Pessoa Jr (2011) faz um mapeamento de algumas atitudes tomadas por cientistas e humanistas em relação ao misticismo quântico. A primeira delas se refere aos adeptos do misticismo quântico, que é constituído em sua maioria por pessoas com uma predisposição a uma visão mística de mundo e que não entendem muito bem a FQ, mas confiam nos livros de divulgação. $\mathrm{O}$ segundo grupo não compartilha das teses do misticismo quântico, mas o respeita. Como parte deste, estão os pós-modernistas, que negam que haja verdades únicas e questionam o direito que nossa cultura teria de impor verdades sobre outras, e os agnósticos, que consideram que existe um valor de verdade para certas afirmações, mas que evitam tomar uma posição até que as questões sejam examinadas exaustivamente pela ciência. Porém, a atitude mais comum entre os cientistas é de simplesmente ignorar o misticismo quântico, ridicularizando-o. Há também um grupo que se autodenomina "cético" e é bastante ativo em desmascarar fraudadores e pseudocientistas. Por fim, o autor apresenta uma atitude mais pluralista, que consistiria em admitir que existem dezenas de interpretações da FQ e que qualquer uma que não seja refutável e autocontraditória deve ser admitida como uma possibilidade, incluindo interpretações idealistas que terminam por construir uma física da alma, por exemplo. Seria uma atitude que considera que tanto essas interpretações idealistas como as interpretações realistas são baseadas em atos de fé (PESSOAJR, 2011). Apesar de talvez ser difícil chegar a um consenso sobre a atitude mais adequada a ser adotada por cientistas e educadores em ciência em relação ao misticismo quântico, dependendo da concepção educacional adotada, algumas atitudes podem ser mais interessantes do que outras. 
Por fim, a última questão filosófica a ser elencada neste trabalho é a questão de uma definição ou delimitação mais precisa do que poderia ser abarcado no termo "misticismo quântico". Pigozzo (2021) identifica que, na literatura que trata desse fenômeno cultural, há várias utilizações do termo sem um consenso preciso. Ao tratar desta questão, Grim (1982) defende que o misticismo quântico atua no âmbito das implicações da FQ e não na FQ em si. Pessoa Jr (2011) ressalta que esse fenômeno pode ser classificado como um fenômeno cultural por sua forte e ampla disseminação na mídia e em boa parte da sociedade. Porém, amplia o escopo delimitado por Grim (1982), incluindo não apenas implicações da FQ, mas também algumas interpretações dessa teoria, ao especificar que seriam interpretações "que se inserem na tradição do naturalismo animista (com seu idealismo transformador) ou que adotam um idealismo subjetivista, ou ainda que partem de elementos religiosos" (PESSOA JR, 2011). O autor também apresenta as principais teses aceitas por algumas correntes místico-quânticas, que incluem interpretações e aplicações da FQ que envolvem as relações entre o observador e o observado, a consciência e a comunicação humana, extensões místicas para a FQ e suas aplicações a outras áreas do conhecimento (PESSOA JR, 2011). Saito (2019) também chama a atenção para o fato de que alguns dicionários de filosofia reconhecem que o termo "misticismo" adquiriu um significado pejorativo. Pessoa Jr (2007-2011), de fato, reconhece que o termo "misticismo quântico" passou a ser adotado por críticos ao movimento e propõe uma distinção entre os termos "misticismo" e "espiritualismo", para cunhar o termo mais amplo "espiritualismo quântico", o qual se refere a uma classe de visões de mundo, que engloba tanto o misticismo quântico, quanto visões que defendem uma abordagem mais racional às relações entre espiritualidade e $F Q$, as quais consistiriam em visões mais próximas da ciência e da filosofia analítica. Dessa forma, para o autor, o termo "misticismo quântico" deve se referir apenas às visões que aceitam que haja um conhecimento intuitivo, não-racional e não-científico a respeito de dimensões espirituais ou transcendentais da realidade, e que defendem que esse conhecimento primordial tem conexões com a física quântica (PESSOAJR, 2007-2011). Outras características mencionadas a respeito da utilização deste termo destacam a sua origem histórico-social, como proveniente do movimento sociocultural denominado "Nova Era" ou "Neoesoterismo", que ressurgiu nas décadas de 1980 a 1990, herdeiro da contracultura hippie das décadas de 1960 a 1970 (PESSOA JR, 2011). Saito (2019) também destaca que esse fenômeno surgiu da circulação 
das ideias e debates na FQ, em um contexto com uma predisposição social geral e uma predisposição específica favoráveis, isto é, da circulação das ideias tanto na própria comunidade de físicos, quanto em outras comunidades na sociedade mais ampla. Por fim, Cruz (2011) destaca o papel da indústria cultural e dos interesses mercadológicos envolvidos no desenvolvimento desse fenômeno. No entanto, diante de todos esses aspectos, ainda permanecem as seguintes questões: que outras características do fenômeno cultural do misticismo quântico ajudariam a delimitar o seu uso e sua abrangência? Deveria haver um consenso maior sobre a utilização desse termo? Ou seria interessante manter uma certa maleabilidade, uma vez que o fenômeno ainda possui muitos aspectos a serem estudados?

Finalmente, com as questões elencadas nesta seção, não se pretendeu esgotar todas as possibilidades de explorar filosoficamente o fenômeno do misticismo quântico, mas elencar algumas possibilidades de partida, as quais podem ser expandidas futuramente.

\section{Perspectiva social e educacional}

A partir do panorama histórico e filosófico a respeito da gênese e do desenvolvimento do fenômeno cultural do misticismo quântico, foi possível perceber que esse fenômeno surgiu da circulação das ideias da FQ não somente na comunidade de físicos que trabalhavam com a FQ, mas também em diversas comunidades presentes na sociedade, o que permitiu com que esse fenômeno se desenvolvesse e ganhasse a repercussão atual (SAITO, 2019). Sendo assim, olhar para esse fenômeno a partir de uma perspectiva social mais ampla permitiria uma reflexão mais precisa e aprofundada a respeito dos seus impactos e efeitos negativos na sociedade. Para isso, seria importante identificar quais são as comunidades envolvidas nesse processo e compreender o seus interesses, modos de funcionamento e o contexto sociocultural no qual elas estão imersas. Em particular, para cientistas e educadores em ciências, o principal interesse nesse estudo reside nas consequências desse fenômeno para a ciência e para a EC e o papel desta última em enfrentar os seus efeitos negativos. 
Por conta da sua origem histórico-social a primeira e, talvez, mais relevante comunidade envolvida no misticismo quântico consiste nos adeptos aos movimentos da Nova Era e do Neoesoterismo. Segundo Rocha (2015), esse movimento é mais apolítico, conformista e próximo à literatura de autoajuda, em relação à contracultura hippie que o antecedeu. Heelas (1996) também destaca que ele possui uma tendência de ser epistemologicamente individualista, apresenta uma forma de humanismo altamente otimista, comemorativa, utópica e espiritual, na qual a autoridade reside na experiência do eu interior ou no reino natural e bastante importância é dada para uma ética própria. Magnani (1999), por sua vez, utiliza a expressão Neoesoterismo para designar a forte expansão e disseminação, em âmbito mundial, das práticas comumente agrupadas sob a denominação de "esotéricas", que incluem uma ampla gama de produtos, atividades e serviços. O autor também mostra que, em geral, o seu público é mais exigente, informado e se dedica a buscar informação e aprofundamento nos assuntos, através de diversas atividades de formação, como palestras, workshops, cursos, etc. O "ethos" do Neoesoterismo pode ser caracterizado pela presença de terapias corporais, pelo cultivo da individualidade, pela existência de uma comunidade inserida em um circuito urbano, pela centralidade da noção de "energia", pela preocupação com a ecologia e a natureza, e pela redescoberta do "feminino" (MAGNANI, 1999).

Após os anos 1990, além das comunidades da Nova Era e do Neoesoterismo, diversas outras comunidades passaram a fazer parte da onda de misticismo quântico. Para ajudar a identificar essas comunidades, um estudo interessante é o de Moura e Santos (2017), que identificaram a presença de livros que continham as palavras "quântica" ou "quântico" em seus títulos e sinopses, nos catálogos online das quatro maiores livrarias do Brasil, os quais se enquadravam em diferentes áreas do conhecimento como: administração, ciências biológicas, direito, engenharia, filosofia, física, história, informática, psicologia, química, autoajuda, esoterismo, medicina 
alternativa, literatura e religião. Nas categorias que envolvem as ciências exatas, como engenharia, física, informática e química, provavelmente, a palavra "quântica" está vinculada aos usos do meio científico. As categorias referentes à filosofia, história e literatura podem estar relacionadas à filosofia, à história da FQ e a livros de divulgação científica. As categorias de autoajuda e esoterismo possivelmente estão relacionadas às comunidades da Nova Era e do Neoesoterismo, analisadas anteriormente. Mas as demais categorias podem apontar para as demais comunidades envolvidas no fenômeno cultural do misticismo quântico.

A comunidade relacionada às categorias de medicina alternativa, ciências biológicas e psicologia possivelmente é outra das mais relevantes nesse fenômeno cultural. Essa relevância se deve a autores como o médico indiano Deepak Chopra, com seu livro A cura quântica (1989), e o físico indiano Amit Goswami, com seu livro O médico quântico (2004), que deslocam o discurso da Nova Era e o vinculam a temas como cura, saúde, alimentação, psicologia popular, etc., inaugurando as chamadas medicina e psicologia quânticas. Esses discursos e comunidades vieram acompanhados de uma poderosa engrenagem comercial, que, além de livros, inclui DVDs, CDs, filmes, seminários, palestras e workshops com grande sucesso de vendas (HAMMER, 2004; NOGUEIRA, 2010). A partir destes autores, muitos outros passaram a veicular esses discursos, o que pode ser ilustrado pelos livros: Psicologia Quântica (2007), de Robert Anton Wilson; e O poder da autocura (2021), de Wallace Lima. As obras posteriores de Chopra e Goswami também passaram a abranger outros temas que vão desde sucesso pessoal, profissional e criatividade, passando por religiosidade, alma, fenômenos parapsicológicos, reencarnação e Deus, até a economia e os conflitos sociais. Suas obras e seu sucesso de vendas inspiraram diversos outros autores, que deram sequência a esses temas, em diversas áreas do conhecimento. Na parte da religião, por exemplo, nota-se que o discurso do misticismo quântico não se restringiu a temas ligados à religiosidade no geral, mas passaram a permear os discursos de religiões específicas, conforme pode ser observado nos livros: Ciência e fé: o reencontro pela Física Quântica (2013), de Robson L. Rodovalho; e O Jesus Quântico (2019), de Marcelo Tezelli. Na área relacionada à administração 
de empresas, nota-se que esse discurso também foi vinculado ao sucesso no mundo empresarial, o que pode ser observado nas seguintes obras: Em busca da empresa quântica (1998), de Clemente Nobrega; e Planejamento Quântico (2015), de Gerald Harris. Por fim, esse discurso também pode ser encontrado na área do direito, nos trabalhos: O Direto Quântico (1971), de Goffredo Telles Jr; e Teoria quântica do direito (2008), de Túlio Lima Vianna.

Assim, diante dessa ampla disseminação do discurso do misticismo quântico, em diversas áreas do conhecimento, restam diversas questões a serem compreendidas, dentre elas: quais as características desses discursos e como eles foram propagados em cada uma dessas áreas do conhecimento? Quais os significados, usos e adaptações que a FQ adquiriu em cada uma delas? Como esse fenômeno ganhou tamanha repercussão? Quais os interesses envolvidos nessa ampla disseminação da FQ? Quais os mecanismos sociais e elementos culturais que possibilitaram a sua popularização? Quais os problemas, implicações sociais e efeitos negativos que os usos e disseminação da FQ neste formato podem suscitar?

Em relação aos mecanismos sociais e elementos culturais que possibilitaram a gênese e o desenvolvimento do fenômeno do misticismo quântico, Saito (2019) destaca o papel das palavras e das pessoas como elementos que circulam entre diferentes comunidades, capazes de promover a circulação das ideias em diferentes meios e, consequentemente, causar uma alteração ou transformação em seus usos e significados. Em particular, as palavras e ideias podem circular através de diferentes elementos culturais. Além dos livros, já mencionados anteriormente, Lima (2017) dá destaque a textos de divulgação científica de revistas com alta circulação entre o público mais amplo e nota que alguns deles procuram a adesão do público através de mecanismos discursivos utilizados por livros de autoajuda. A autora aponta que isso provavelmente se deve ao interesse comercial que esse tipo de revista possui. Lima et al. (2021), por sua vez, analisam o álbum Quanta (1997), de Gilberto Gil, e mostram que a arte também pode ter um papel importante na propagação de imagens sobre ciência. Sendo assim, restaria identificar outros mecanismos sociais e elementos culturais relevantes nesse processo. 
Outros aspectos sociais relevantes a serem analisados nesse fenômeno se referem a como a FQ é apresentada nos discursos dos místicos quânticos, os interesses envolvidos e os problemas, implicações sociais e efeitos negativos suscitados. Machado (2017) denuncia a presença de desvios e apropriações indébitas de conceitos da FQ no discurso de livros místicos quânticos, apontando que eles possuem objetivos e intencionalidades distintas do proposto pelo conhecimento científico original. Sobre os efeitos negativos na sociedade suscitados por esses desvios, o autor corrobora com Cruz (2011) ao apontar os interesses mercadológicos envolvidos nesses discursos e a utilização do conhecimento científico como uma mercadoria pela indústria cultural. Oliveira (2018) corrobora com esses autores, chamando a atenção para a existência de empresas que comercializam "produtos quânticos" - como suplementos alimentares, florais, etc. - e mostrando o exemplo de uma empresa que costuma fazer parcerias com um grupo educacional e com um sindicato de terapeutas alternativos, para a promoção de cursos e eventos. Oliveira (2018) também denuncia a existência de um curso de especialização lato-sensu, intitulado "Saúde Quântica", que foi aprovado pelo Ministério da Educação brasileiro (MEC), o qual é promovido por esse grupo educacional, em parceria com a empresa de "produtos quânticos" mencionada. Rocha (2015), por sua vez, destaca o papel do Instituto Esalen, nos EUA, nos anos 1970, no surgimento desses "produtos quânticos" e relata que esse mercado consolidou-se no Brasil em 2009, quando iniciou-se a realização dos Simpósios de Saúde Quântica e Qualidade de Vida, também conhecidos como ExpoQuantum. Em 2013, essa feira reuniu cerca de 5000 pessoas e 119 expositores, que promoviam terapias alternativas usando explicações da FQ. Atualmente, essas terapias e produtos são fortemente difundidos e comercializados em diferentes partes do mundo. Dessa forma, nota-se que os principais problemas do misticismo quântico atual se referem à distorção dos conceitos da $\mathrm{FQ}$ e a sua utilização para fins que não se restringem à física, mas que visam justificar uma suposta confiabilidade de produtos relacionados à tratamentos de saúde, para atender demandas mercadológicas promovidas pela indústria cultural. Outro aspecto preocupante é a promoção de cursos - inclusive, de pós-graduação reconhecidos pelo MEC - com parcerias com essas empresas de "produtos quânticos", que, por um lado, refletem a mercantilização da educação e, por outro, difundem um conhecimento distorcido a respeito da FQ e, consequentemente, disseminam desinformação a respeito dessa área da física. 
Além desses aspectos problemáticos, Nogueira (2010) e Saito (2019) chamam a atenção para o fato de que, nos discursos do misticismo quântico atual, o termo "quântico" se transformou em um símbolo de autoridade persuasiva, que se baseia em argumentos de autoridade científica para sustentar afirmações diversas, adquirindo um caráter dogmático, no qual a FQ é vista como uma verdade inquestionável, o seu conhecimento completo é restrito a poucos indivíduos e a aceitação da sua importância requer obediência e docilidade (SAITO, 2019). Saito (2019) também mostra a presença de uma desvalorização da "ciência tradicional" nestes discursos - a qual é vinculada ao "velho paradigma" representado pela FC - e uma busca pela construção de uma "ciência alternativa", uma nova ciência revolucionária, supostamente mais humana e subjetiva - a qual é vinculada ao "novo paradigma" da FQ - como uma herança dos discursos da Nova Era. A presença desses elementos se assemelha a alguns discursos de movimentos da era da pós-verdade, os quais têm trazido grandes prejuízos à confiabilidade na ciência por parte da sociedade. Por fim, Diem e Lewis (1992) também criticam o orientalismo - isto é, a tendência de simplificação e idealização das filosofias orientais, a fim de criticar a sociedade ocidental - presente na obra de Fritjof Capra e em diversos outros autores ocidentais, que fazem paralelos entre a FQ e as formas de pensamento orientais. Dessa forma, nota-se que outro problema destes discursos é que eles dependem de uma postura acrítica por parte dos indivíduos a quem se dirigem, que estes se contentem com argumentos de autoridade, rejeitem a ciência convencional, se interessem pela proposta de uma "ciência alternativa" e aceitem simplificações e idealizações a respeito de outras culturas e filosofias. Assim, as implicações e os problemas advindos desse fenômeno cultural não somente atingem a sociedade em geral, mas têm consequências mais graves, especialmente para a ciência e para a educação.

Diante desse contexto, o papel da EC e, em particular, do Ensino de Física, parece ser crucial nessa discussão e na busca de soluções para esses problemas. Porém, nesse ponto, a questão principal passa a ser: qual EC? O que é essencial e deve ser priorizado nesse processo? Quais as possibilidades a serem trabalhadas?

Diversos autores destacam a importância e a urgência de se trabalhar a FM e, em especial, a parte mais conceitual da FQ, no Ensino Médio (CRUZ; CRUZ, 2009; MACHADO, 2017; OLIVEIRA, 2018; MASSONI; BRITO, 2021). Contudo, outros autores destacam as dificuldades para que isso se torne uma realidade, como a ausência de discussão mais conceitual acerca das diferentes interpretações da FQ nos 
cursos usuais de MQ (MONTENEGRO; PESSOA JR, 2002) e nos livros didáticos de MQ adotados nesses cursos (CRUZ; CRUZ, 2009). Também apontam que essas discussões seriam importantes para instrumentalizar os cidadãos para analisar e agir mais criticamente frente aos problemas dos discursos do misticismo quântico, incluindo as suas apropriações indébitas (CRUZ; CRUZ, 2009; MACHADO, 2017), e que estas não deveriam se restringir apenas à aquisição de competências individuais, mas que busquem um empoderamento social e uma problematização coletiva dos temas tratados (MACHADO, 2017; SAITO, 2019). Outros autores destacam a importância de se trabalhar FM na escola, não apenas em seus aspectos conceituais, mas também em seus aspectos históricos e epistemológicos mais amplos (MASSONI; BRITO, 2021), incluindo os processos de circulação do conhecimento científico (SAITO, 2019). Alguns sugerem que o fenômeno do misticismo quântico poderia ser um dos pontos de partida para a discussão de FM no Ensino Médio, além de ser um tema oportuno para discutir as diferenças entre a ciência e a pseudociência e preparar os cidadãos para avaliar as informações que recebem pelos diferentes meios (PESSOA JR, 2013; OLIVEIRA, 2018). Porém, outros alertam para tipo de abordagem a ser utilizada nestas discussões (VENEZUELA, 2008; SAITO; GURGEL, 2016; LIMA, 2017; HOERNIG, 2020).

Ao fazer esse resgate e lançar um olhar sobre os principais estudos relacionados ao tema em discussão, não se pretendeu fechar as questões apresentadas, mas, ao contrário, elencar pontos de partida e contraposições para que sejam feitas novas investigações. Dessa forma, o debate permanece em aberto: quais outras possibilidades de se discutir e buscar soluções para os problemas suscitados pelo fenômeno cultural do misticismo quântico? Quais outras formas de se promover uma EC mais crítica e humanizada? 


\section{Considerações finais}

O fenômeno cultural do misticismo quântico é um fenômeno complexo e multifacetado, que toca em diversas questões que envolvem desde a natureza da ciência e as fronteiras entre o conhecimento científico e o não científico, passando por questões filosóficas e de fundamento da $\mathrm{FQ}$, até as suas implicações para a ciência e para a EC. Neste trabalho, buscou-se apresentar um panorama dos principais temas relacionados a esse fenômeno, que têm sido explorados nos últimos anos, a fim de identificar possibilidades de pesquisa em aberto. Para isso, os temas foram apresentados a partir das perspectivas histórica, filosófica, social e educacional.

Conclui-se que ainda existem muitas possibilidades de análise desse fenômeno que tem intrigado físicos, filósofos, historiadores e educadores da ciência, em especial, nas áreas de história, filosofia e sociologia da ciência e na compreensão e na busca de soluções para os seus impactos na ciência e na EC. Espera-se que este trabalho tenha contribuído para fornecer um panorama geral dos problemas em aberto, que seja um ponto de partida para novas investigações e que inspire outros pesquisadores a explorarem o tema.

\section{The Cultural Phenomenon of Quantum Mysticism: possibilities and perspectives of research}

\section{Abstract}

The cultural phenomenon of quantum mysticism has been a source of many different reactions in physicists, science educators and researchers in Physics Teaching. This occurs because of the wide popularization the term "quantum" has acquired in the last decades, off-site physics. This is a complex and multi-sided phenomenon, which encompasses several issues, such as the nature of science, frontiers between scientific and non-scientific knowledge, the foundations of quantum physics and the implications to science and Scientific Education. The aim of the present work is to present an overview of the main topics related to this phenomenon, which has been investigated in the last years, and identify new possibilities of research. The topics will be presented in historical, philosophical, social and educational perspectives. It was concluded that there are still many possibilities of analysis of this phenomenon in history, philosophy and sociology of science research areas and in search of a better comprehension and of solutions for its impacts in science and Science Education. It is hoped that this work can contribute to provide a good overview and be a start point of future possible research topics and that it can inspire other researchers to explore the subject.

Keywords: Quantum physics, Mysticism, Popularization of Science, Circulation of Knowledge, Science and Culture. 


\section{Notas}

1 Orientalismo é um termo utilizado para se referir aos estudos acerca das civilizações orientais. Esses estudos se baseiam em uma distinção ontológica e epistemológica entre "o Oriente" e "o Ocidente". Em 1978, Edward W. Said, em sua obra Orientalismo: a invenção do Oriente pelo Ocidente lança uma crítica, denunciando a visão eurocêntrica acerca dessas civilizações enraizada nesses estudos, os interesses envolvidos na imagem construída sobre "o Oriente" e, portanto, a distorção e a falta de precisão ao tratar dessas civilizações.

2 O termo "bricolagem" se refere a ideia de uma técnica improvisada, adaptada às circunstâncias ou um conserto feito de maneira não muito ortodoxa (KASPER, 2006 apud OLIVEIRA, 2018).

\section{Referências}

BELLER, Mara. Quantum dialogue: the making of a revolution. Chicago: University Of Chicago, 1999.

CAPRA, Fritjof. O Tao da Física: um paralelo entre a Física Moderna e o Misticismo Oriental. São Paulo: Ed. Cultrix, 1983. Original em inglês: The Tao of Physics: An Exploration of the Parallels Between Modern Physics and Eastern Mysticism. Boston: Shambhala, 1975.

COSTA, Thiago Tavares da. A apropriação do termo "quântico": de que forma a física moderna e contemporânea é divulgada por outras áreas do conhecimento. Rio de Janeiro: CEFET/RJ, 2013. Dissertação (Mestrado), Centro Federal de Educação Tecnológica Celso Suckow da Fonseca, 2013.

CRUZ, Frederico Firmo de Souza. Mecânica Quântica e a cultura em dois momentos. In: FREIRE JR, O.; PESSOA JR, O.; BROMBERG J. L. (Org.). Teoria Quântica: Estudos Históricos e Implicações Sociais. Campina Grande: EDUEPB/Livraria da Física, 2011.

CRUZ, Frederico Firmo de Souza; CRUZ, Sônia Maria de Souza. Pode o ambiente cultural e social definir o conteúdo escolar de física: o caso da Mecânica Quântica. Anais do VII Encontro Nacional de Pesquisa em Educação em Ciências, Florianópolis, 2009.

DIEM, Andrea Grace; LEWIS, James R. Imagining India: The Influence of Hinduism on the New Age Movement. In: LEWIS, James R.; MELTON, J. Gordon. (orgs.). Perspectives on the New Age. Albany: State University of New York Press, 1992. p. 48-58

FORMAN, Paul. A cultura de Weimar, a causalidade e a teoria quântica, 1918-1927: A adaptação dos físicos e matemáticos alemães a um ambiente intelectual hostil. Cadernos de História e Filosofia da Ciência supl. 2, p. 3-98, 1983.

FREIRE JR., Olival. The Quantum Dissidents: rebuilding the foundations of Quantum Mechanics (1950-1990). Springer Heidelberg New York Dordrecht London, 2015.

FREIRE JR, Olival; PESSOA JR, Osvaldo; BROMBERG Joan Lisa. (Org.). Teoria Quântica: Estudos Históricos e Implicações Sociais. Campina Grande: EDUEPB/Livraria da Física, 2011.

GRIM, Patrick. (Org.). Philosophy of science and the occult. 2.ed. Albany: Sunys, 1982.

HAMMER, Olav. Claiming knowledge: strategies of epistemology from theosophy to the New Age. Leiden; Boston: Brill, 2004.

HEELAS, Paul. The new age movement: the celebration of the self and the sacralization of modernity. Oxford: Blackwell, 1996.

HOERNIG, André Felipe. Física Quântica e História e Filosofia da ciência: conceitos, vida, crenças e religiosidade como motivadores na aprendizagem de Física. Porto Alegre: UFRGS, 2020. Dissertação (Mestrado), Instituto de Física, Universidade Federal do Rio Grande do Sul, 2020. 
IMPROBABLE REASEARCH. Ig Nobel Prize Winners. Disponível em: < https://www.improbable. com/ig/winners/\#ig1998>. Acesso em: 31 set. 2021.

JAMMER, Max. The Conceptual Development of Quantum Mechanics. New York: McGrawHill, 1966.

KAISER, David. How the hippies saved physics: science, counterculture, and the quantum revival. New York, London: W.W. Norton \& Company, 2011.

KRAGH, Helge. Quantum generations: a history of physics in the twentieth century. Princeton: Princeton University Press, 1999.

LIMA, Jane Hellen Gomes de. Circulação da ciência: relações entre o discurso referente à ciência e o discurso de autoajuda. Florianópolis: UFSC, 2017. Dissertação (Mestrado), Centro de Ciências Físicas e Matemáticas, Universidade Federal de Santa Catarina, 2017.

LIMA, Nathan Willig; MORAES, Andreia Guerra de; MONTEIRO, Abigail Vital de Goes. "Cântico dos cânticos, quântico dos quânticos": as relações dialógicas entre artes, ciências contemporâneas e saúde no álbum Quanta, de Gilberto Gil. História, Ciências, Saúde - Manguinhos, Rio de Janeiro, v. 28, n. 1, p. 187-209, jan.-mar. 2021.

MACHADO, Sandro da Silva Livramento. Implicações culturais da teoria quântica: caminhos metafóricos e apropriações indébitas. Florianópolis: UFSC, 2017. Tese (Doutorado), Programa de Pós-graduação em Educação Científica e Tecnológica, Universidade Federal de Santa Catarina, 2017.

MAGNANI, José Guilherme. Mystica urbe: um estudo antropológico sobre o circuito neo-esotérico na metrópole. São Paulo: Studio Nobel, 1999.

MARIN, Juan Miguel. "Mysticism" in quantum mechanics: the forgotten controversy. European Journal of Physics, v. 30, p. 807-822, 2009.

MASSONI, Neusa Teresinha; BRITO, Alan Alves. Física Quântica e o Ensino de Física na contemporaneidade: reflexões à luz da história e da epistemologia revisada de Popper. Experiências em Ensino de Ciências v. 16, n. 1, p. 331-348, 2021.

MOURA, Mairus Disconzi; SANTOS, Renato P. dos. Detectando misticismo quântico em livros publicados no Brasil com Ciência de dados. Caderno Brasileiro de Ensino de Física, v. 34, n. 3, p. 725-744, dez. 2017.

MONTENEGRO, Roberto Luiz; PESSOA JR, Osvaldo. Interpretações da Teoria Quântica e as concepções dos alunos do curso de Física. Revista Investigações em Ensino de Ciências, v. 7, n. 2, p. 107-126, 2002.

NOGUEIRA, Pablo. Espiritualidade quântica? Consciência, religião e ciência no pensamento de Amit Goswami. São Paulo: PUC-SP. Dissertação (Mestrado), Pontifícia Universidade Católica de São Paulo, 2010.

OLIVEIRA, Maria Luiza de. Desvios de conceitos da teoria quântica pela bricolagem de não cientistas. Campinas: Unicamp. Dissertação (Mestrado), Instituto dos Estudos da Linguagem, Universidade de Campinas, 2018.

PATY, Michel. The problem of the physical interpretation of theoretical quantities and the intelligibility of the quantum domain. Science and cultural diversity: Proceedings of the XXIst International Congress of History of Science, Changes in Interpretation \& Conceptual Contents, 2774-2793, 2005.

PESSOA JR, Osvaldo. Análise de um típico argumento místico-quântico. In: SILVA, Cibelle Celestino; PRESTES, Maria Elice Brzezinski (orgs.). Aprendendo ciência e sobre sua natureza: abordagens históricas e filosóficas, São Carlos, 2013. 
PESSOAJR, Osvaldo. O fenômeno cultural do misticismo quântico. In: FREIRE Jr, Olival; PESSOA Jr, Osvaldo; BROMBERG, Joan Lisa. (Org.). Teoria Quântica: estudos históricos e implicações culturais. Campina Grande: EDUEPB; São Paulo: Livraria da Física, 2011. p. 281-302.

PESSOA JR, Osvaldo. Física Quântica: Entenda as diversas interpretações da física quântica, 2007-2011. Disponível em: <http://www2.uol.com.br/vyaestelar/fisicaquantica.htm >.

PESSOAJR, Osvaldo. Introdução Histórica à Teoria Quântica, aos seus problemas de fundamento e às suas interpretações. Caderno de Física da UEFS 04(01 e 02), p. 89-114, 2006.

PESSOA JR, Osvaldo. Conceitos de Física Quântica. Volume I. São Paulo: Editora Livraria da Física, 2003.

PESSOA JR, Osvaldo. O sujeito na física quântica. In: OLIVEIRA, Eduardo Chagas. (Org.). Epistemologia, lógica e filosofia da linguagem: ensaios de filosofia contemporânea. Feira de Santana: Núcleo de Estudos Filosóficos, p. 157-196, 2001.

PESSOA JR, Osvaldo. O problema da medição em Mecânica Quântica: um exame atualizado. Cadernos de História e Filosofia da Ciência v. 2, n. 2, p. 177-217, 1992.

PIGOZZO, Daniel. Do Místico ao Quântico: o emaranhamento de cosmovisões no desenvolvimento da Física Moderna e Contemporânea. Porto Alegre: UFRGS, 2021. Dissertação (Mestrado), Instituto de Física, Universidade Federal do Rio Grande do Sul, 2021.

PIGOZZO, Daniel; LIMA, Nathan Willig; NASCIMENTO, Matheus Monteiro. A filosofia sistêmica de Fritjof Capra: um olhar ecológico para a Física e para o Ensino de Física. Caderno Brasileiro de Ensino de Física, v. 36, n. 3, p. 704-734, dez. 2019.

ROCHA, Gustavo Rodrigues. O Profeta e o Metafísico: uma história cultural do reencantamento do mundo pela Teoria Quântica através da vida e obra de Fritjof Capra e Henry Stapp. Salvador: UFBA/UEFS, 2015. Tese (Doutorado), Programa de Pós-graduação em Ensino, Filosofia e História das Ciências. Universidade Federal da Bahia/Universidade Estadual de Feira de Santana, 2015.

SAITO, Marcia Tiemi. A gênese e o desenvolvimento da relação entre física quântica e misticismo e suas contribuições para o ensino de ciências. São Paulo: USP, 2019. Tese (Doutorado), Programa Interunidades em Ensino de Ciências, Universidade de São Paulo, 2018.

SAITO, Marcia Tiemi; GURGEL, Ivã. “Quantum healing”: Science, popular Science, pseudoscience or myth? Na analysis based on Ludwik Fleck. In: PIETROCOLA, Maurício; GURGEL, Ivã; LEITE, Cristina. (eds.), MOMETTI, Carlos (ass.). Contemporary science education and challenges in the presente society: perspectives in physics teaching and learning. São Paulo: FEUSP, 203-208, 2017.

SAITO, Marcia Tiemi; GURGEL, Ivã. Misticismo Quântico: resistência de professores em formação inicial em trabalhar as relações entre Ciência e Cultura em sala de aula. Anais do XVI Encontro de Pesquisa em Ensino de Física, Natal, 2016.

VENEZUELA, Osvaldo Dias. Demarcando ciências e pseudociências para alunos do Ensino Médio. São Paulo: USP, 2008. Dissertação (Mestrado), Instituto de Física, Instituto de Química, Instituto de Biociências, Faculdade de Educação, Universidade de São Paulo, 2008.

WILBER, Ken. Quantum questions: mystical writings of the world's great physicists. Boston: Shambhala Publications Inc., 1984. 